\title{
PENGEMBANGAN MULTIMEDIA PEMBELAJARAN INTERAKTIF BERBASIS \\ LECTORA INSPIRE PADA PELAJARAN INSTALASI PENERANGAN LISTRIK DI SMK SWASTA DWIWARNA MEDAN
}

\author{
Anwar Saleh ${ }^{1}$, Sahat Siagian ${ }^{2}$ \\ ${ }^{1,2}$ Pendidikan Teknik Elektro, Fakultas Teknik Universitas Negeri Medan \\ 1 anwarsaleh0@gmail.com, ${ }^{2}$ sahatsgn@gmail.com
}

\begin{abstract}
The purpose of this research is to develop interactive learning multimedia in the form of an interactive CD, using several software including Lectora Inspire, Adobe Photoshop CS6, Bandycam, and AMR to MP3 Converter. This development research used the Borg and Gall research model adapted from Sugiyono. The target of this research is the Expert Lecturer at the State University of Medan. The eligibility test of interactive learning multimedia was carried out by media validators, material validators, and acceptance validators. Based on the data analysis conducted, it shows that the resulting learning multimedia is good with a score of 4.4 for material validation, a score of 4.5 for media validation, and a score of 4.2 for validation of acceptances. So the results of the validation show that the learning multimedia developed is eligible for use.
\end{abstract}

\section{Key Words: Interactive Multimedia, Lectora Inspire Software, Electrical Lighting Installation}

\begin{abstract}
Abstrak
Tujuan dari penelitian ini adalah mengembangkan multimedia pembelajaran interaktif dalam bentuk CD interaktif, menggunakan beberapa software diantaranya Lectora Inspire, Adobe Photoshop CS6, Bandycam, dan AMR to MP3 Converter. Penelitian pengembangan ini menggunakan model penelitian Borg and Gall yang diadaptasi dari Sugiyono. Sasaran penelitian ini adalah Dosen Ahli Universitas Negeri Medan. Uji kelayakan multimedia pembelajaran interaktif dilakukan oleh validator media, validator materi, dan validator penerimaan. Berdasarkan analisis data yang dilakukan menunjukkan bahwa multimedia pembelajaran yang dihasilkan baik dengan skor validasi materi 4,4, validasi media skor 4,5, dan validasi penerimaan skor 4,2. Sehingga hasil validasi menunjukkan bahwa multimedia pembelajaran yang dikembangkan layak untuk digunakan.
\end{abstract}

\section{Kata Kunci: Multimedia Interaktif, Software Lectora Inspire, Instalasi Penerangan Listrik}

\section{PENDAHULUAN}

Dalam meningkatkan kualitas pendidikan, seorang guru berperan bukan hanya mentrasferkan ilmunya melalui buku akan tetapi seorang guru dapat menggunakan ICT (Information Communication and Technology)dengan alat bantu multimedia interaktif menggunakan bermacam-macam software yang dipadukan dengan bentuk-bentuk media visual seperti video untuk menciptakan serta mengembangkan metode dan materi pembelajaran yang menarik agar dapat meningkatkan keefektifan dalam proses pembelajaran sehingga kualitas pendidikan menjadi lebih baik.ICT memiliki kemampuan yang sangat luar biasa untuk menyampaikan informasi.Penggunaan media secara tepat dan bervariasi dapat mengatasi kejenuhan peserta didik dalam belajar.Media yang digunakan bukan hanya satu, tetapi lebih dari satu media atau multimedia (teks, grafik, gambar, audio, visual) yang dapat disajikan dalam waktu yang bersamaan.Multimedia pembelajaran memiliki keunggulan dibandingkan media lain, hal ini karena penggabungan seutuhnya teknologi komputer dari multimedia pembelajaran, audio serta video yang dikombinasikan dengan baik sehingga dapat meningkatkan perhatian peserta didik terhadap informasi yang disampaikan. Interaktif artinya ada balikan yang diberikan oleh media kepada peserta didik yang memberikan perintah kepada media yang digunakan. 
Tabel 3.1 Angket Pra Penelitian

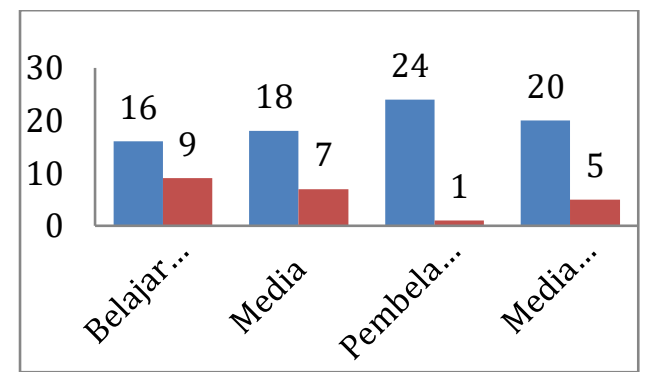

Berdasarkan angket pada pra penelitian diperoleh data dari 25 peserta didik kelas XI TITLdi SMK Swasta Dwiwarna Medan bahwa dalam memahami pelajaran Instalasi Penerangan Listrik peserta didik mengalami kesulitan dalam proses pembelajaran karena pendidik masih menggunakan media yang sederhana, yakni powerpoint. Berdasarkan angket tanggapan peserta didik yang telah disebarkan kepada 25 peserta didik, sejumlah 16 peserta didik berpendapat sumber belajar yang digunakan adalah modul pembelajaran tanpa menggunakan media sebanyak 18 peserta didik berpendapat mereka jarang mendapatkan suatu media berupa software, sebanyak 24 peserta didik menyukai pembelajaran dengan tampilan dan isi yang menarik, dan sebanyak 20 peserta didik belum pernah menggunakan media pembelajaran instalasi penerangan listrik dalam bentuk multimedia berupa aplikasi Lectora Inspire.

Wawancara pendidik pelajaran IPL (Instalasi Penerangan Listrik) memberikan informasi bahwa dalam proses pembelajaran minat belajar peserta didik pada saat belajar IPL masih kurang. Pendidik menyatakan penggunaan multimedia pembelajaran seperti power point, video pembelajaran yang ditampilkan menggunakan LCD didepan kelas sudah digunakan.Namun karena pembelajaran masih berpusat pada pendidik dalam menjelaskan serta keterbatasan pendidik dalam mengembangkan media pembelajaran, peserta terkesan belajar monoton serta jenuh sehingga kurang termotivasi dan konsentrasi.Pendidik juga belum menemukan multimedia interaktif dengan model pembelajaran yang sesuai khususnya pada materi IPL.Peserta didik membutuhkan media pembelajaran inovatif, baru.Hasil analisis beberapa data tersebut,makasoftware yang digunakan sebagai media pembelajaran seperti Lectora Inspire diperlukan dalam proses pembelajaran.

Lectora Inspire merupakan program yang efektif dalam membuat media pembelajaran.Lectora Inspire merupakan software pengembangan belajar elektronik (e-learning) yang relatif mudah diaplikasikan atau diterapkan karena tidak memerlukan pemahaman bahasa pemrograman yang canggih.Lectora Inspire menyediakan template yang siap digunakan untuk memasukkan materi pembelajaran, selain itu di dalam Library Lectora Inspire sudah terdapat banyak gambar, animasi, karakter animasi yang dapat kita gunakansecara langsung dan dapat digunakan untuk menggabungkan flash, merekam video, menggabungkan gambar, dan screen capture.

Telah dilakukan penelitian-penelitian sebelumnya terkait multimedia pembelajaran interaktif lectora Inspire.A. Puri Laksani, I G. Ratnaya, dan I P. Suka Arsa dalam hasil pengembangannya berupa media pembelajaran interaktif teknik listrik dan elektronika berbasis lectora inspire 17. Angga Kurniawan dan Yudha Anggana Agung dalam penelitiannya tentang pengembangan media pembelajaran interaktif menggunakan lectora inspire pada mata pelajaran teknik elektronika dasar.Benny Santho Yosep dalam penelitan tentang pengembangan media pembelajaran interaktif berbasis Lectora Inspire dalam pembelajaran Instalasi Penerangan Listrik. Penelitian yang dilakukan oleh Maria Veronika Simanjuntak yang meneliti pengembangan multimedia berbasis adobe flash CS3 untuk pembelajaran instalasi penerangan listrik.

\section{METODE}

Penelitian ini menggunakan model Research and Development (R\&D) dengan metode yang digunakan yakni Borg and Gall yang diadopsi oleh Sugiyono. Tahapan penelitian tersebut meliputi potensi dan masalah, pengumpulan informasi, desain produk, validasi desain, revisi desain, uji coba desain, revisi produk, uji coba pemakaian, revisi produk, dan produk massal. Pengembangan multimedia interaktif berbasis Lectora Inspire pada pelajaran Instalasi Penerangan Listrik akan dilakukan hanya sampai tahap kelima yaitu revisi desain. 
1. Potensi dan Masalah

Potensi adalah segala sesuatu yang bila didayagunakan akan menjadi nilai tambah, sedangkan masalah adalah penyimpangan antara yang diharapkan dengan yang terjadi. Masalah pun dapat menjadi potensi bila kita bisa mendayagunakannya.Berdasarkan angket yang disebar terhadap peserta didik terkait penggunaan media pembelajaran yang digunakan dalam pembelajaran memberikan informasi bahwa peserta didik masih jarang menggunakan media pembelajaran berupa software sehingga pembelajaran terkesan monoton.Peserta didik membutuhkan media pembelajaran inovatif.Multimedia interaktif yang mempermudah mereka belajar. Bagi pendidik adanya penggunaan atau pemanfaatan multimedia interaktif membantu kinerja mereka dalam menyampaikan materi dalam proses pembelajaran.

2. Mengumpulkan Informasi

Masalah yang ditemukan pada pra penelitian dijadikan sebuah potensi bagi peneliti sehingga dikumpulkan berbagai informasi mengenai media pembelajaran. Peneliti mencari informasi melalui jurnal, buku, dan internet untuk mengetahui penelitian yang menunjang media pembelajaran berikut cara pengoperasian dari media tersebut. Hasil dari pengumpulan informasi peneliti mendapatkan suatu media pembelajaran berupa multimedia interaktif yaitu Lectora Inspire.

3. Desain Produk

Pada tahap ini terdapat rancangan pembuatan media yang akan dibuat dalam media pembelajaran. Untuk media pembelajaran ini dibuat tidak linier, agar pengguna (Peserta Didik) lebih mudah menggunakan segala tombol tanpa harus ke halaman sebelumnya, ini dimaksudkan jika peserta didik berada di halaman kepustakaan dan ingin masuk ke halaman test, maka peserta didik langsung saja mengklik tombol test dan langsung ke halaman test tanpa harus menekan tombol kembali terlebih dahulu.

Dalam desain awal ini masih banyak halaman yang belum ditampilkan, desain diatas masih merupakan tampilan dari topic utama dari sebuah media pembelajaran, untuk halaman isi materi, video materi, symbol, dan animasi materi tidak jauh berbeda dengan desain diatas namun akan lebih detail.

Dalam tahap pengembangan media ada beberapa software pendukung, yakni Adobe Flash CS6 untuk membuat tampilan yang menarik dan Adobe Photoshop CS6 untuk mengedit gambar atau tombol navigasi menjadi lebih menarik.

4. Validasi Desain

Validasi desain merupakan proses kegiatan untuk menilai apakah rancangan produk berupa media secara rasional akan lebih efektif karena validasi bersifat penilaian berdasarkan pemikiran rasional belum fakta lapangan. Validasi desain dilakukan berkaitan dengan multimedia pembelajaran interaktif pada pelajaran Instalasi Penerangan Listrik terdiri dari dua ahli, yaitu:

a. Validasi Materi

Validasi materi dilakukan untuk mengetahui kelayakan dari setiap aspek pada materi yang disajikan yang meliputi aspek kelayakan isi, kelayakan penyajian, kelayakan bahasa, dan penilaian kontekstual.Validator materi dilakukan oleh Dosen Universitas Negeri Medan.

b. Validasi Media

Validasi media bertujuan untuk mengetahui kelayakan dari setiap aspek pada media yang dikembangkan yang meliputi aspek komunikasi visual dan rekayasa perangkat lunak.Validator media dilakukan oleh Dosen Universitas Negeri Medan.

c. Validasi Akseptansi

Validasi akseptansi bertujuan untuk mengetahui kelayakan dari aspek pengguna multimedia yang meliputi aspek desain dan fasilitas media serta efek pedagogi. Validator akseptansi dilakukan oleh Dosen Universitas Negeri Medan

5. Revisi Desain

Revisi desain bertujuan untuk memperbaiki kelemahan yang didapat setelah dilakukan validasi oleh validator ahli pada tahap sebelumnya. Kekurangan diketahui dari hasil validasi dan saran dari pakar pada proses validasi. Revisi produk ini digunakan untuk menghasilkan multimedia pembelajaran interaktif yang lebih baik. 


\section{HASIL PENGEMBANGAN DAN PEMBAHASAN}

Hasil penelitian pengembangan multimedia pembelajaran interaktif ini adalah pengembangan multimedia berbasis Lectora Inspire pada pelajaran Instalasi Penerangan Listrik. Produk multimedia yang telah berhasil dikembangkan untuk langkah penelitian selanjutnya dilakukan penyebaran instrument untuk mengetahui validasi para ahli terhadap multimedia Lectora Inspire. Validasi terhadap multimedia ini dilakukan oleh ahli materi dan ahli media. Berdasarkan validasi ahli materi dan validasi media pembelajaran diperoleh:

1. Validasi Materi

Hasil validasi materi terhadap produk multimedia interaktif berbasis Lectora Inspire pada pelajaran Instalasi penerangan listrik ditampilkan pada table 4.1 berikut ini.

Tabel 1 Hasil Validasi Materi

\begin{tabular}{|c|c|c|c|c|c|c|c|}
\hline No & \multicolumn{2}{|c|}{ Aspek Media } & $\begin{array}{c}\text { Panduan } \\
\text { dan }\end{array}$ & $\begin{array}{c}\text { Materi } \\
\text { Multimedia }\end{array}$ & Evaluasi & Total & $\begin{array}{c}\text { Mean skor \& } \\
\text { Penilaian }\end{array}$ \\
\hline \multirow{3}{*}{1} & \multirow{3}{*}{ Penilai 1} & Jlh skor & 19 & 50 & 37 & 106 & 4,4 \\
\hline & & Jlh skor & 4 & 12 & 8 & 24 & Sangat layak \\
\hline & & Total & 4,7 & 4,1 & 4,6 & & \\
\hline \multirow{3}{*}{2} & \multirow{3}{*}{ Penilai 2} & Jlh skor & 18 & 53 & 37 & 108 & 4,5 \\
\hline & & Jlh skor & 4 & 12 & 8 & 24 & Sangat layak \\
\hline & & Total & 4,5 & 4,4 & 4,6 & & \\
\hline \multirow{2}{*}{3} & \multirow{2}{*}{\multicolumn{2}{|c|}{ Total Skor }} & 37 & 103 & 74 & \multirow{2}{*}{\multicolumn{2}{|c|}{214}} \\
\hline & & & 8 & 24 & 16 & & \\
\hline 4 & \multicolumn{2}{|l|}{ Mean Skor } & 4,6 & 4,7 & 4,6 & & 4,4 \\
\hline 5 & \multicolumn{2}{|c|}{ Hasil Penilaian } & $\begin{array}{l}\text { Sangat } \\
\text { layak }\end{array}$ & $\begin{array}{l}\text { Sangat } \\
\text { layak }\end{array}$ & $\begin{array}{l}\text { Sangat } \\
\text { layak }\end{array}$ & \multicolumn{2}{|c|}{ Sangat layak } \\
\hline
\end{tabular}

Dari validasi materi diperoleh hasil sebesar 4,6 pada aspek panduan dan informasi, 4,7 pada aspek konten/materi multimedia serta 4,6 pada aspek evaluasi. Validasi dari ahli materi memperoleh rata-rata sebesar 4,4. Hasil validasi terhadap produk oleh ahli materi tersebut dalam kategori "Sangat Layak".

\section{Validasi Media}

Validasi terhadap hasil pengembangan multimedia interaktif berbasis Lectora Inspire pada mata pelajaran instalasi penerangan listrik oleh ahli media dapat dilihat dalam table 4.2 berikut.

Tabel 2 Hasil Validasi Media

\begin{tabular}{|c|c|c|c|c|c|c|c|}
\hline No & \multicolumn{2}{|c|}{ Aspek Media } & $\begin{array}{l}\text { Panduan } \\
\text { dan } \\
\text { Informasi }\end{array}$ & $\begin{array}{l}\text { Operasional } \\
\text { Multimedia }\end{array}$ & $\begin{array}{c}\text { Sistematika, } \\
\text { Estetika, } \\
\text { dan Prinsip } \\
\text { Rekabentuk } \\
\text { Media }\end{array}$ & Total & $\begin{array}{c}\text { Mean skor \& } \\
\text { Penilaian }\end{array}$ \\
\hline \multirow{3}{*}{1} & \multirow{3}{*}{ Penilai 1} & Jlh skor & 15 & 47 & 113 & 175 & 4,6 \\
\hline & & Jh skor & 3 & 10 & 25 & 38 & Sangat layak \\
\hline & & Total & 5 & 4,7 & 4,5 & & \\
\hline \multirow{3}{*}{2} & \multirow{3}{*}{ Penilai 2} & Jlh skor & 14 & 47 & 107 & 168 & 4,4 \\
\hline & & Jlh skor & 3 & 10 & 25 & 38 & Sangat layak \\
\hline & & Total & 4,6 & 4,7 & 4,2 & & \\
\hline \multirow{2}{*}{3} & \multirow{2}{*}{\multicolumn{2}{|c|}{ Total Skor }} & 29 & 94 & 220 & \multirow{2}{*}{\multicolumn{2}{|c|}{343}} \\
\hline & & & 6 & 20 & 50 & & \\
\hline 4 & \multicolumn{2}{|l|}{ Mean Skor } & 4,8 & 4,7 & 4,4 & & 4,5 \\
\hline 5 & \multicolumn{2}{|c|}{ Hasil Penilaian } & $\begin{array}{l}\text { Sangat } \\
\text { layak }\end{array}$ & $\begin{array}{l}\text { Sangat } \\
\text { layak }\end{array}$ & $\begin{array}{l}\text { Sangat } \\
\text { layak }\end{array}$ & \multicolumn{2}{|c|}{ Sangat layak } \\
\hline
\end{tabular}


Validasi media memperoleh hasil sebesar 4,8 pada aspek panduan dan informasi, 4,7 pada aspek operasional multimedia serta 4,4 pada prinsip dan rekabentuk Media. Validasi dari ahli media memperoleh rata-rata sebesar 4,5. Hasil validasi terhadanproduk oleh ahli media tersebut dalam kategori "Sangat Layak".

\section{Validasi Akseptansi}

Hasil validasi akseptansi terhadap produk multimedia interaktif berbasis Lectora Inspire pada pelajaran Instalasi penerangan listrik ditampilkan pada table 4.3 berikut ini.

Tabel 3. Hasil Validasi Akseptansi

\begin{tabular}{|c|c|c|c|c|c|c|c|c|c|}
\hline No & \multicolumn{2}{|c|}{ Aspek Media } & $\begin{array}{c}\text { Panduan } \\
\text { dan } \\
\text { Informas } \\
i\end{array}$ & $\begin{array}{l}\text { Materi } \\
\text { media }\end{array}$ & Evaluasi & $\begin{array}{c}\text { Desain } \\
\text { dan } \\
\text { Fasilita } \\
\text { s } \\
\text { Media }\end{array}$ & $\begin{array}{c}\text { Efek } \\
\text { Pedagogi }\end{array}$ & $\begin{array}{l}\text { Tot } \\
\text { al }\end{array}$ & $\begin{array}{l}\text { Mean skor } \\
\text { \& Penilaian }\end{array}$ \\
\hline \multirow{2}{*}{1} & \multirow{2}{*}{ Penilai } & $\begin{array}{l}\text { Jhh } \\
\text { skor }\end{array}$ & 15 & 52 & 22 & 45 & 22 & 156 & 4,2 \\
\hline & & $\begin{array}{l}\text { Jhh } \\
\text { skor }\end{array}$ & 4 & 13 & 5 & 10 & 5 & 37 & $\begin{array}{l}\text { Akseptansi } \\
\text { sangat tinggi }\end{array}$ \\
\hline 2 & \multicolumn{2}{|c|}{ Mean Skor } & 3,75 & 4 & 4,4 & 4,5 & 4,4 & & 4,2 \\
\hline 3 & \multicolumn{2}{|c|}{ Hasil Penilaian } & $\begin{array}{l}\text { Akseptan } \\
\text { si tinggi }\end{array}$ & $\begin{array}{c}\text { Aksep } \\
\operatorname{tansi} \\
\text { tinggi }\end{array}$ & $\begin{array}{c}\text { Akseptan } \\
\text { si sangat } \\
\text { tinggi }\end{array}$ & $\begin{array}{c}\text { Aksept } \\
\text { ansi } \\
\text { sangat } \\
\text { tinggi }\end{array}$ & $\begin{array}{c}\text { Akseptans } \\
\text { i sangat } \\
\text { tinggi }\end{array}$ & \multicolumn{2}{|c|}{$\begin{array}{c}\text { Akseptansi sangat } \\
\text { tinggi }\end{array}$} \\
\hline
\end{tabular}

Validasi akseptansi memperoleh hasil sebesar 3,75 pada aspek panduan dan informasi, 4 pada aspek materi media, 4,4 pada aspek evaluasi, 4,5 pada aspek desain dan fasilitas media, serta 4,4 pada aspek efek pedagogi. Validasi akseptansi memperoleh rata-rata sebesar 4,2. Hasil validasi akseptansi terhadap produk tersebut dalam kategori "Akseptansi Sangat Tinggi”.

Adapun produk akhir pengembangan multimedia pembelajaran interaktif berbasis Lectora Inspire telah selesai dilakukan setelah melalui tahap uji kelayakan pada ahli materi dan ahli media.Produk akhir tersebut dapat digunakan pada jenjang SMK sebagai media pembelajaran.

Tabel 4. Produk Multimedia Interaktif Berbasis Lectora Inspire
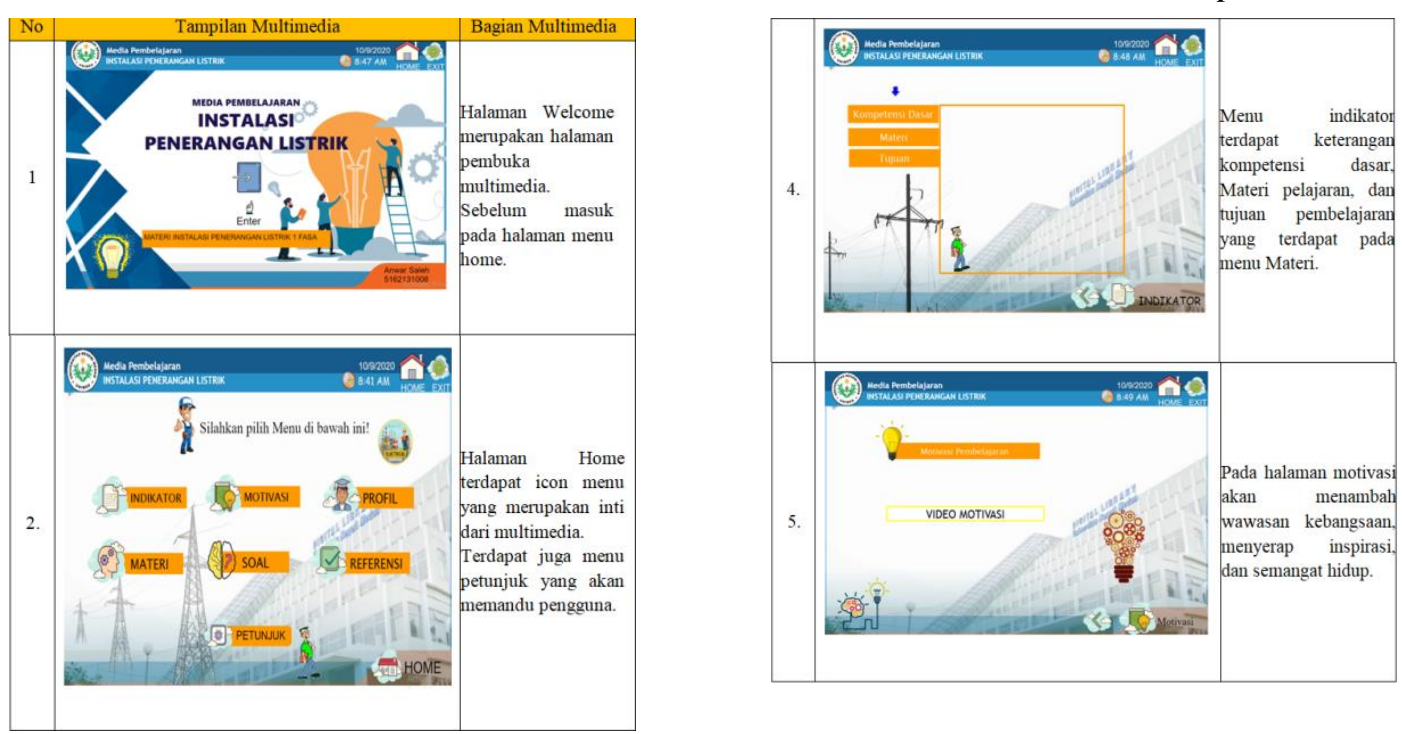

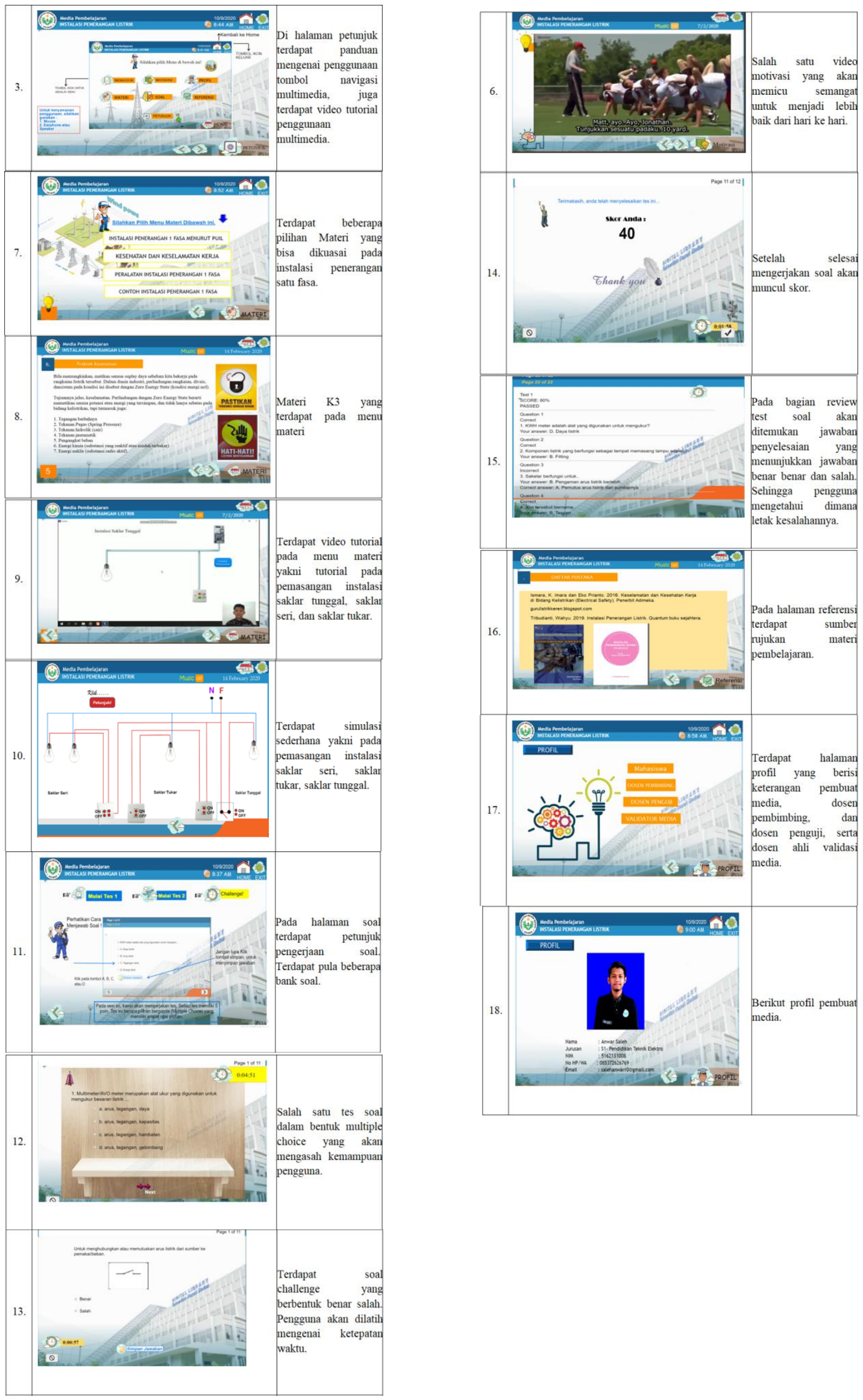


\section{Pembahasan}

a. Pengumpulan data

Berdasarkan hasil dari identifikasi potensi dan masalah kemudian dilakukan langkah penelitian yaitu pengumpulan data agar kebutuhan peserta didik dapat diketahui mengenai produk yang dikembangkan. Langkah pertama peneliti melakukan analisis kebutuhan dengan cara membagikan angket. Berdasarkan angket tersebut diketahui peserta didik dalam pembelajaran instalasi penerangan listrik merasa kurang tertarik karena belajar terkesan monoton dan membosankan.Tidak ada variasi dalam pembelajaran dan hanya menggunakan sumber belajar berupa buku paket, sehingga perlu adanya suatu media belajar yang dapat menarik minat peserta didik terhadap materi pembelajaran.

b. Desain produk

Tahapan yang harus dilakukan dalam desain produk multimedia interaktif berbasis Lectora Inspire pada pelajaran instalasi penerangan listrik antara lain penentuan ide pembuatan media, analisis materi untuk membuat media, video pembelajaran, simulasi sederhana, dan gambar yang diperoleh dari beberapa situs internet. Terdapat pula beberapa video dari youtube. Setelah dimuat dalam Lectora Inspire, maka multimedia pembelajaran interaktif siap di publish ke dalam beberapa format publikasi.

Desain multimedia interaktif mempertimbangkan kepada:

1) Pengguna

Multimedia interaktif ini dibuat untuk mempermudah proses belajar dan meningkatkan minat peserta didik di SMK Swasta Dwiwarna Medan.

2) Peralatan output

Multimedia interaktif akan digunakan secara mandiri oleh peserta didik maka diperlukan format yang kompatibel terhadap jenis komputer yang akan digunakan oleh peserta didik baik dirumah maupun di rental komputer serta warung internet.

3) Gambar

Multimedia interaktif ini disertai dengan gambar seperti pada latar belakang dan ilustrasi.

4) Audio

Untuk audio yang digunakan pada Multimedia interaktif ini diputar otomatis pada saat materi di buka dan peserta didik menekan tombol OFF jika ingin menghentikan suara yang ada pada materi, untuk Audio yang lain tidak terlalu banyak dengan alasan suara dapat mengganggu konsentrasi belajar dan jika diperlukan audio untuk penyegaran peserta didik dapat menggunakan audio yang terdapat pada komputer yang digunakan.

5) Animasi

Animasi ditampilkan sesuai dengan materi yang dibahas sehingga peserta didik dapat melihat ilustrasi gambar dari materi yang dipelajari.

6) Video

Video disajikan dalam bentuk video dimana peserta didik dapat melihat videonya pada saat materi ditampilkan.

7) Test

Test disediakan pada menu test di media pembelajaran tersebut.

Desain pengembangan multimedia pembelajaran interaktif, dikerjakan menggunakan Lectora dan dikemas dalam bentuk CD. Media pembelajaran ini dibangun dalam bentuk CD bertujuan untuk mempermudah peserta didik dalam belajar, dimana media dalam bentuk CD ini dapat digunakan tidak hanya disekolah saja, tetapi juga dapat digunakan dirumah atau bahkan memanfaatkan fasilitas-fasilitas umum seperti warnet dan rental computer. Pemanfaatan bentuk $\mathrm{CD}$ ini dapat mendorong peserta didik yang pergi ke warnet untuk browsing sekaligus mempelajari bahan belajar yang termuat didalam CD interaktif ini.

Dalam desain dan pengembangan CD interaktif ini faktor-faktor berikut menjadi perhatian utama, yaitu:

1) Penyajian informasi

2) Penggunaan media

3) Kemudahan penggunaan

4) Kemanfaatan 
Materi yang termuat di dalam multimedia masih sebatas kepada beberapa sub kompetesnsi yang tetap saling berkaitan, sehingga walaupun hanya terdiri dari beberapa sub kompetensi media tetap memiliki nilai pengetahuan yang dibutuhkan untuk mencapai tujuan pembelajaran yang sesuai dengan kurikulum. Keterbatasan materi ini dikarenakan keterbatasan waktu dalam penelitian.

Materi dalam CD interaktif terdiri dari:

a) Petunjuk penggunaan

Petunjuk penggunaan berisikan informasi yang mengarahkan peserta didik agar lebih mudah memahami penggunaan dan cara belajar menggunaan multimedia interaktif ini.

b) Profil Penulis

Profil Penulis berikan informasi tentang riwayat singkat penulis.Serta dosen pembimbing, dosen penguji, serta dosen ahli media dan ahli materi.

c) $\mathrm{KD}$

KD berisikan tentang kompetensi dasar yang harus dicapai oleh peserta didik.

d) Materi

Materi ini terdiri dari 3 sub kompetensi yang berbentuk kalimat yang didalamnya terdapat simulasi dalam bentuk gambar dan video.

e) Tes

Tes dibuat dalam bentuk pilihan ganda dan true or false serta setiap masing-masing test tertera skor yang diraih oleh peserta didik pada saat menjawab tes.

CD yang digunakan adalah CD-RW, ini dimaksudkan karena peneliti memperhatikan ukuran file pembelajaran yang tidak terlalu besar serta faktor ekonomis bahan dapat dijangkau oleh peserta didik ketika ingin memiliki CD interaktif tersebut, serta dapat menambah materi yang baru ke dalam CD jika dibutuhkan.

Adapun produk akhir pengembangan multimedia pembelajaran interaktif berbasis Lectora Inspire telah selesai dilakukan setelah melalui tahap uji kelayakan pada ahli materi dan ahli media. Sehingga produk akhir tersebut layak digunakan pada jenjang SMK sebagai media pembelajaran.

\section{SIMPULAN}

Berdasarkan hasil penelitian dan pengembangan media pembelajaran interaktif yang dilakukan, produk pengembangan multimedia diawali dengan penyebaran angket guna menganalisis masalah. Kemudian mendesain produk pembelajaran sesuai dengan satu KD pembelajaran yang berisi indikator, motivasi, materi, soal, dan profil. Finalisasi produk media adalah dengan melakukan validasi kepada validator, yaitu ahli materi dan ahli media. Setelah melakukan validasi didapatkan saran dan masukan dari validator kemudian direvisi sehingga menjadi produk akhir multimedia pembelajaran.

Hasil validasi ahli materi terkategori sangat layak dengan rata-rata nilai 4,4 dan validasi dari ahli media terkategori sangat layak dengan rata-rata 4,5. Hasil validasi Akseptansi media terkategori sangat tinggi dengan rata-rata 4,2. Sehingga produk akhir dari pengembangan multimedia pembelajaran interaktif berbasis Lectora Inspire pada pelajaran instalasi penerangan listrik layak dipakai dalam jenjang SMK pada proses pembelajaran.

\section{DAFTAR PUSTAKA}

Arsyad, Azhar. (2014). Media Pembelajaran.Jakarta: PT Rajagrafindo Persada.

Asim.(2001). Sistematika Penelitian Pengembangan. Malang: Lembaga Penelitian-Universitas Negeri Malang.

Benny Santho Yosep. (2017). "Pengembangan Media Pembelajaran Interaktif Menggunakan Lectora Inspire Dalam Pembelajaran Instalasi Penerangan Listrik Kelas XI". Skripsi. Medan. Universitas Negeri Medan.

Borg W.R. and Gall M.D. (1983). Educational Research: An Introduction, 4th edition (London: Longman Inc.)

Hanafi.(2017). Konsep Penelitian R\&D Dalam Bidang Pendidikan. Saintifika Islamica: Jurnal Kajian Keislaman. Volume 4, No.2.http://jurnal.uinbanten.ac.id/index.php/ saintifikaislamica/article/ download/1204/953/ (diakses pada 10 Januari 2020). 
Irfan, Muhammad dan Lusia Rakhmawati.(2017). Pengembangan Media Pembelajaran Menggunakan Software Lectora Inspire Pada Mata Pelajaran Teknik Listrik di SMK Negeri 2 Bojonegoro. Jurnal Pendidikan Teknik Elektro. Volume 06 Nomor 01.http://jurnalmahapeserta didik.unesa.ac.id/ index.php/jurnal-pendidikan-teknik-elektro/article/ download/18183/16572 (diakses pada 10 Januari 2020).

Isjoni, Mohd. Arif Ismail dan Rosnani Mahmud.(2008). ICT Untuk Sekolah Unggul. Yogyakarta: Pustaka Belajar.

Kurniawan, Angga dan Yudha Anggana Agung. (2016). Media Pembelajaran Interaktif Menggunakan Lectora Inspire Pada Mata Pelajaran Teknik Elektronika Dasar Untuk SMKN 2 Surabaya. Jurnal Pendidikan Teknik Elektro. Volume 05, Nomor 03.https://jurnalmahapeserta didik.unesa.ac.id/ index.php/jurnal-pendidikan-teknik-elektro/article/ view/ 16817/15281. (diakses pada 10 Januari 2020).

Laksani. A. Puri, I G. Ratnaya dan I P. Suka Arsa. (2018). Pengembangan Media Pembelajaran Interaktif Teknik Listrik dan Elektronika Berbasis Lectora Inspire 17. Jurnal Pendidikan Teknik Elektro Undiksha. Vol 8, No. 2.https://ejournal.undiksha.ac.id/ index.php/JJPTE/ article/view/20224/ 12282 (diakses pada 10 Januari 2020).

Maria Veronika Simanjuntak. (2015). "Pengembangan Multimedia Berbasis Adobe Flash CS3 Untuk Pembelajaran Instalasi Penerangan ListrikKelas XI”. Skripsi. Medan. Universitas Negeri Medan.

Mega Astutik dan Puput Wanarti Rusimamto.(2016). "Pengembangan Media Pembelajaran Multimedia Interaktif Berbantuan Software Lectora Inspire Untuk Meningkatkan Hasil Belajar Pada Mata Pelajaran Teknik Listrik di SMK Negeri 2 Surabaya."Jurnal Pendidikan Teknik Elektro,V5 No.1. https://jurnalmahapeserta didik.unesa.ac.id/index.php/jurnalpendidikan-teknik-elektro/article/view/13731/4830 (diakses pada 10 Januari 2020).

Nana Sudjana, Ahmad Rivai. (2002). Media Pengajaran. Bandung: Sinar Baru Algensindo.

Nursamsu dan Teuku Kusnafizal.(2017). Pemanfaatan Media Pembelajaran ICT Sebagai Kegiatan Pembelajaran Peserta didik di SMP Negeri Aceh Tamiang.Jurnal IPA dan Pembelajaran IPA (JIPI), 1(2). jurnal.unsyiah.ac.id/JIPI/article/view/9691 (diakses pada 09 Januari 2020).

Purnama, Sigit. (2013). Metode Penelitian dan Pengembangan. Literasi, Volume. IV, No. 1.http://almaata.ac.id/ejournal1532/index.php/LITERASI/article/ download/70/69 (diakses pada 10 Januari 2020).

Rusman, Deni Kurniawan dan Cepi Riyana.(2015). Pembelajaran Berbasis Teknologi Informasi dan Komunikasi “Mengembangkan Profesional Guru”.Jakarta: Rajawali Pers.

Shalikhah, Norma Dewi, Ardhin Primadewi dan Muis Sad Iman. (2017). Media Pembelajaran Interaktif Lectora Inspire Sebagai Inovasi Pembelajaran.Warta LPM.Vol 20, No 1.Journals.ums.ac.id/Index.php/ warta/artikel/download (diakses 09 Januari 2020).

Sriadhi, 2018.Instrumen Penilaian Multimedia Pembelajaran. Medan: Universitas Negeri Medan.

Sugiyono. (2015) Metode Penelitian Pendidikan (Pendekatan Kuantitatif, Kualitatif, dan $R$ D) Bandung: Alfabeta,

Sugiyono.(2015). Metode Penelitian dan Pengembangan. Bandung: Alfabeta.

Yayan, Yulianto (2012) Media Pembelajaran Sebagai Alat Bantu Dalam Meningkatkan Suatu Proses Dan Hasil Pembelajaran.Universitas Negeri Yogyakarta. https://eprints.uny.ac.id/9432/ (diakses pada 10 Januari 2020). 